\title{
A Study on the Development of Innovation and Entrepreneurship Education for University Students in Jilin Province
}

\author{
Lin $\mathrm{Lv}^{1, \mathrm{a}}$ and Xijun Ou $\mathrm{u}^{2, \mathrm{~b}}$ \\ ${ }^{1}$ School of Media and Mathematics \& Physics, Jilin Engineering Normal University, Changchun, \\ China \\ ${ }^{2}$ Scientific Research Office, Jilin Engineering Normal University, Changchun, China \\ a380939313@qq.com, ${ }^{\text {b2287460790@qq.com }}$
}

\begin{abstract}
Keywords: Innovation and entrepreneurship education; Jilin province; General universities; Development
\end{abstract}

\begin{abstract}
A survey was made of the development of innovation and entrepreneurship education for the students in general universities in Jilin Province. Through a comparison with that of similar universities in other provinces, some problems and defects were found out together with relevant strategies for optimization. This will offer a help to further improvement of the education in the future.
\end{abstract}

\section{Introduction}

The education of innovation and entrepreneurship, composed of education both on innovation and on entrepreneurship, is an integral part of quality education for university students and important foundation for them to start their own businesses. For a general university, sufficient attention should be paid to offer such an education to improve students' comprehensive qualities, awareness of innovation and entrepreneurship and practical capabilities in business starting-up, and as a result improve their success rate in startup practice and employment rate. Late as it was started, the education has already been relatively successful through the efforts by the government, educational departments and universities [1]. To describe the development of the education in the universities in Jilin Province, the paper presents a survey on the basis of a review on certain relevant literature.

\section{Basic Connotation of Innovation and Entrepreneurship Education for University Students and Its Practical Significance}

Of the 2 concepts in the education, innovation means the behavior to create a different product or pattern on the basis of one's initiative and breakthroughs in new thoughts, inventions or descriptions, and entrepreneurship is a process in which novel products or service is created and then transformed into productivity for value growth. The former leads to and is the foundation of the latter, while the latter is the form and vehicle of the former. For a university, it may be an effective means to improve the students' creativity, initiative and practical capabilities by offering the education combining both of the two. Besides, the education will also help to widen the job market and reduce the pressure from job placement by improving students' awareness and thoughts of innovation, practical capabilities in starting of business as well as their comprehensive qualities and core competitive edges in the stage when the number of university graduates keeps increasing due to the expansion of higher education enrollment.

\section{Process and Status of the Development of Innovation and Entrepreneurship Education in China}

It was in 1998 when the Ministry of Education mentioned that universities should pay due attention to the education for improving students' capabilities in innovation and practice as well as their initiative. 
In 1999, the Ministry announced that universities should reinforce the entrepreneurship education for both students and teachers and encourage them to start hi-tech businesses for the first time in the Action Scheme for Invigorating Education towards the $21{ }^{\text {st }}$ Century. In fact, the appeal corresponds to the situation that employment rate began to drop year by year from that year of 1999 when university enrollment was expanded. And since 1999, China began to try many possible means to develop the education and encourage students to start their own business for a higher employment rate. In 2006, Entrepreneurship Education in China-Trial and Practice, a book compiled by the Ministry, further illustrated fundamental concepts, meaning, goals and characteristics of entrepreneurship education. 4 years later, the Business Guiding Scheme was launched by the Ministry of Education, the Ministry of Finance and the Ministry of Human Resources and Social Security jointly with a goal to guide 450,000 university graduates to start their businesses within 3 years. In August 2012, a notification about Basic Teaching Requirements on Entrepreneurship Education in General Higher Learning Institutions was issued by the Ministry of Education, which helped with the scientific and systemized development of the innovation and entrepreneurship education for university students. On May 14, 2015, the Ministry of Education, out of the attention to the education in universities, issued the Implementation Opinions on Deepening the Reform of Innovation and Entrepreneurship Education in Universities, putting forward the overall requirements on the job for the universities [2].

\section{Introduction Development of Innovation and Entrepreneurship Education in the Universities in Jilin Province}

According to the Implementation Opinions on Promoting University Students' Innovation and Business Starting through Deepening Reforms of Education and Teaching in Universities by Jilin Provincial Government in Sept. 2015, the Department of Education of Jilin Province demanded that supports of intelligence and human resources be provided for the education of innovation and entrepreneurship. As a result, relevant courses have been offered by some universities in the province. For example, Jilin University of Agriculture offered a 1-credit 16-hour course of Innovating Engineering Practice worth 1 credit, a 2-credit 32-hour course of Startups Management, a 1.5-credit 20-hour course of Job Placement Guidance and a 2-credit 32-hour course of Fundamentals of Business Starting with over 20 full-time or part-time teachers. In 2015, a series of courses including Career Placement Situation and Policies and Guidance of Business Starting and Job Placement were offered as required ones by Jilin Engineering Normal University after the foundation of the school's Innovation and Entrepreneurship Center of Students. In Jilin Business and Technology College, 4 full-time and 5 part-time teachers were appointed as lecturers of a required course of Entrepreneurship Education and a elective course of Entrepreneurship Strategies. In Northeast Electric Power University, over 20 full-time and part-time teachers were responsible for a required course of Entrepreneurship and Job Placement Education and 2 elective courses of Entrepreneurs Incubation and Theories and Practice of Business Starting. Another university worthy of being noted is Changchun Guanghua University where school-based textbooks were written for 2 required courses of Career Planning of University Students and Job Placement Guidance and other similar courses like Professional Qualities Promotion of College Students, Entrepreneurship Education for College Students, etc [3].

Besides offering relevant courses to the students, some universities in Jilin Province increased the investment in the construction of enterprise incubation gardens and sci-tech gardens. In Sept. 2016, the Department of Education of Jilin Province announced that 29 bases like "Lintian Makers Park" were listed as the first incubation bases for university students' business at the provincial level, 21 bases like "Jilin Provincial Photo electronic Industrial Startup Incubator for University Students" as the first provincial demonstration bases of university students" enterprises, 11 bases like "Tonghua Pharmaceutical Industry Pilot Plant Test Platform of Innovation and Entrepreneurship" as the first provincial sci-tech bases for university students' business starting and practice, and 33 campus-based bases like "Innovation and Entrepreneurship Technical Garden for University Students in Life 
Science" of Jilin University and the "Maker Space" of Changchun Vocational Institute of Technology as the first provincial innovation and business starting bases for university students [4].

\section{Problems in the Education}

It is discovered in the survey that certain successes have been made in the innovation and entrepreneurship education for the students in the universities in Jilin Province owing to sufficient attention paid to the job and quick action taken by the government. However, some problems still exist if compared with that in the universities of similar type in other provinces. For example, some universities failed to place due emphasis to the job in time and only determined to offer relevant courses to the students after certain decision had been made by the provincial government. As a result, neither teachers nor students have developed clear awareness of the significance and connotations of innovation and entrepreneurship education [5]. On the other hand, the education has not been integrated into the whole process of talent cultivation in the universities. Although it is acknowledged that business starting has to be based on innovation, including that in teaching, relevant courses in some universities still follow the traditional exam-oriented mode characterized with passive implantation and fail to develop students' consciousness and views on the importance of innovation. In addition, there are no unified criteria on the curriculum in the field nor standardized textbooks in the universities in Jilin Province. Another well-known defect in higher education is that very few if any universities have enough communication with external social life, resulting in a problem that teachers lack necessary practical experiences. This determines that their teaching is a mere formality instead of effective education. Finally, it has to be admitted that relevant assessment system on the job is far from perfect [6].

\section{Suggestions on the Optimization of the Education}

Pay More Attention to Entrepreneurship Education. A university has to be keenly aware of the significance to provide such education for the students and pay enough attention to the job by making the examples of university students in starting business and national supporting policies known to more people over the radio, TV and other new media platforms to create a favorable atmosphere or environment.

Perfect the Management Mechanism of Entrepreneurship Education. A university should try to perfect the management mechanism related to the education. For example, a leading group to guide the education should be organized including staff from the academic affair office, student affair office, job placement department, Youth League committee in a university to offer an effective guarantee in organization, classroom, human resources and funds.

Improve the Curriculum of Entrepreneurship Education. A university should improve its curriculum of the education by offering required courses like career and job placement guidance or elective courses like innovative thinking training in the module of general education to develop correct attitudes towards job selection, job placement and business starting, optimize their knowledge structure and build their confidence in innovation and business starting. Elective courses like project development training can be offered in the module of professional education to help students understand the process of project development and improve their capabilities in problem discovering and solving. Related elective courses can also be offered in the practical module like SIYB and KAB to certain students with relevant experiences of business operation. From these courses, students will not only learn about related knowledge and processes of business starting but build up their self-confidence and capabilities. Yet it doesn't mean that other fundamental courses for university students can be neglected. On the contrary, the education about innovation and business starting should run through the whole process of higher education to encourage students to transfer their knowledge to productivity driven by a noble ideal [7]. 
Use the Incubator bases of Entrepreneurship in the Universities. Practical courses of innovation and business starting instruction should take full advantage of those incubator bases established in the universities, where top-level trainings will integrate current latest industrial theories and technology into higher education based on the cooperation between enterprises and universities.

Encourage Teachers' Initiative in Entrepreneurship Education. A university should prepare certain incentive policies to improve teachers' initiatives. In the assessments of academic ranks and teaching performance, a teacher's success in instructing students to win certain awards or start certain businesses should be quantified as corresponding workload to encourage him or her to participate in the education of innovation and entrepreneurship. At the same time, teachers of specialized courses should be offered with opportunities to work full-time in the enterprises. In this way, they can acquire necessary practical experiences and help with the cultivation of talents needed by the society and the enterprises.

Improve Relevant Assessment System. A university should improve relevant assessment system. It means that internet shops, companies or small business run by university student should not be taken as significant successes of innovation and business starting education. In other words, universities should encourage students to innovation or start their businesses at a high level. As for project assessment of students, a step-by-step approach should be adopted based on sectional assessment, overall assessment and point accumulation. In a related course, assessment should focus on idea formulation and real or virtual process of business starting with teachers and classmates' reviews as a supplement to guide and encourage the students to put what they learned to practice. In this way, the emphasis will be placed on students' capabilities in problem analysis and solving. In addition, a result and benefit-oriented assessment mechanism should be established so as to avoid the short-sighted development mode that only pursues quantitative growth [8].

\section{Acknowledgements}

The paper is funded by a project of the 13th 5-year program for university sci-tech and social sciences in Jilin Province-Innovation and Entrepreneurship Education for Students in Application-oriented Universities (No. JLKH2017179SK).

\section{References}

[1] X.J. Xue: Journal of Huaihai Institute of Technology (Humanities \& Social Sciences Edition), Vol.11 (2013) No.2, p.126-128.

[2] T. Zhang, C.L. Huang and Y.R. Qin: Education (Digest), Vol. 11 (2015) No.18, p.24.

[3] X.X. Ke: Manager' Journal, Vol. 21 (2014) No.8, p.376.

[4] C.L. Xue, C.C. Lu and D.M. Li: China Higher Education Research, Vol. 33 (2016) No.2, p. $20-28+73$.

[5] D.Y. Wang and Q.T. Lu: Journal of Changchun University of Science and Technology (Social Sciences Edition), Vol. 28 (2015) No.9, p.147-152.

[6] L. Zhang, W.J. Liu and Z.D. Chen, et al.: Scientific Research, (2015) No.17, p.14-15.

[7] L.F. Wang: Petroleum Education, Vol. 21 (2014) No.2, p.82-86.

[8] D.B. Qu: Strategies of Establishment and Implementation of Entrepreneurship Education in Universities (MS., Northeast Normal University, China 2007), p.43-48. 